Pakistan Journal of Humanities and Social Sciences
Volume 9, Number 3, 2021, Pages 281-291
Journal Homepage:
https://journals. internationalrasd.org/index.php/pjhss
PALISTAN JOURNAL OF
SCIENCES (PJHSS)

\title{
Second language acquisition research and materials development: Need to bridge the gap between theory and practice
}

\author{
Shahzad Karim ${ }^{1}$, Abdul Saeed ${ }^{2}$, Naushaba Haq ${ }^{3}$ \\ ${ }^{1}$ Assistant Professor of English, The Islamia University of Bahawalpur, Pakistan. Email: shahzadaps@gmail.com \\ 2 Assistant Professor of English, Sukkur Institute of Business Administration University, Pakistan. \\ Email: saeedabdulskr@gmail.com \\ ${ }^{3}$ Assistant Professor of English, The Islamia University of Bahawalpur, Pakistan. Email: naushabahaq@gmail.com
}

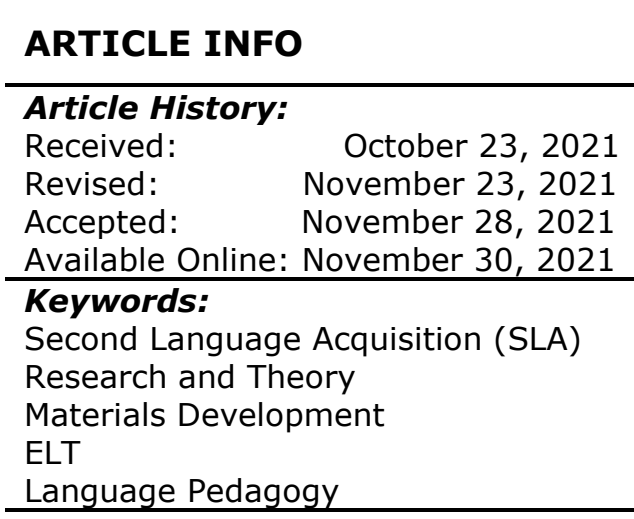

\section{ABSTRACT}

This research paper highlights the issue of the lack of connection between second language acquisition (SLA) theory and research, particularly with regard to language pedagogy and its practical implementation in language teaching materials/textbooks. Based on a theoretical review of the major theoretical perspectives in SLA, the paper underscores that a gap exists between the theory developers (who develop theories through research) and the practitioners (who bear the responsibility for the implementation of theoretical knowledge) in the fields of SLA and materials development. This lack of cohesion between the theory developers and the practitioners causes the development of ineffective English language teaching (ELT) materials which, consequently, fail to make a substantial contribution to effective English language teaching and learning. The paper highlights that it is important to explore SLA theory and research and ensure its implementation in ELT materials. Similarly, there is a need to carry out research about the implementation of SLA theory in materials development and instructed language learning. Such a research will be a significant contribution to the field of materials development and will open new horizons in language pedagogy from both theoretical and practical perspectives.

(c) 2021 The Authors, Published by iRASD. This is an Open Access Article under the Creative Common Attribution Non-Commercial 4.0

Corresponding Author's Email: shahzadaps@gmail.com

\section{Introduction}

Every field of knowledge is based on two important aspects: theory and practice. Based on these two important aspects, the people who are linked with that field of knowledge are usually divided into two groups: one who develop the theoretical constructs (the theory developers) and the other who put the theory into practice (the practitioners). The situation is similar in SLA which is a sub-discipline in the field of applied linguistics. In SLA, the division between the two groups-the theory developers and the practitioners-is clearly visible. The people belonging to the theory developer group (I may subsequently refer to them as the theorists) are mostly academicians and researchers who, based on their empirical research, present new ideas and theories. These theories are often questioned and further explored by the fellow researchers who subsequently add something more to these theories and finally approve or reject them. The other group, that of practitioners (who may subsequently be referred to as the implementers) mainly consists of language teachers, materials/coursebook writers, publishers, and educational administrators who are responsible for the implementation of language learning theories in their respective domains to promote effective language teaching and learning. However, it is a fact that in SLA a wide gap exists between the theorists (academicians and researchers) and the practitioners (language teachers, materials/coursebook writers, publishers and educational administrators) (Ellis, 2010; Nassaji \& Fotos, 2007; Richards, 2006; Tomlinson, 2013, 2016). 


\section{Theoretical background}

The reality of the existing gap between SLA research and its successful implementation in language pedagogy has been widely accepted by researchers (for details, see Ellis, 2010; Nassaji, 2005; Robbins, 2003; Tomlinson, 2013, 2016). In addition, the researchers (Richards, 2006; Tomlinson, 2013, 2016) ascribe to a number of reasons for this existing gap between the SLA theory and its implementation. According to Tomlinson (2013, 2016), an important reason for the gap between the theorists and the practitioners is their lack of interaction. They seldom find opportunities to see each other and exchange their ideas, as they mostly remain confined to their own domains. The conferences and seminars they organise usually remain restricted to their own specific domains. In addition, the research journals and the books where the research is published are not easily accessible to the practitioners. Hence, they hardly find opportunities to connect themselves with the SLA theory and research. Nassaji (2005) found similar results when surveying the teachers of English as a foreign language (EFL). The EFL teachers Nassaji (2005) surveyed reported that they were aware of the importance of SLA research, but they seldom read it. This lack of opportunity for the practitioners to connect themselves with the SLA theory is an important reason for their limited understanding of the technical terminology and its underlying theoretical concepts that are used by the theorists in their research. Further, the wide range of SLA research and its fast pace are two important factors that contribute to the existing gap between the theorists and the practitioners. It is difficult for the practitioners to keep their pace with the researchers. Based on these reasons, the practitioners are mostly unable to keep themselves updated with the latest developments in SLA theory and thus the existing gap between the theorists and the practitioners is widening (Tomlinson, 2013, 2016). Apart from these, there are some other reasons also that add to the existing gap between theory and practice.

From a practical point of view, the high-stake examinations are an important reason for the mismatch between ELT materials/course books and SLA theoretical perspectives (Richards, 2006; Robbins, 2003). The high-stake examinations mostly aim to assess learners' linguistic knowledge of the English language but do not assess their communicative abilities (Tomlinson, 2013). Such examinations are mostly based either on objective type questions which are often related to vocabulary and grammatical items or the short, subjective questions that seek learners' knowledge about the factual information given in the content of the course books (Tomlinson, 2005). It is partly because marking such type of questions is easier for the assessors. In contrast, the assessment of communicative abilities is not only a challenging task for the assessors as they lack assessment skills but is also a time-consuming process. It requires large infrastructural resources. On account of these shortcomings, the assessment of communicative ability is mostly neglected in the examinations. Therefore, the materials/course book designers include only those aspects of the English language in the course books that are relevant to the examinations and are easier to assess.

Additionally, the evaluation studies of ELT materials/course books have revealed that when designing and using the ELT materials/course books, the practitioners are often overwhelmed with the idea of language teaching methodologies/approaches as compared to the idea of language learning principles, and one of its main reasons is their lack of connection with the recent developments in SLA theory and research (Ellis, 2016; Tomlinson, 2013, 2016). Before discussing this idea in detail, it is important to clarify the difference between language teaching methodology/approach and language learning principles. Further, it is important to provide a brief history of the SLA theory and research, as it will help us understand why and how the gap between the SLA theory and practice has widened over the years.

\section{Difference between language teaching methodology/approach and language learning principles}

An important aspect in instructed language learning is practitioners' lack of clarity about the difference between language teaching methodology and language learning principles. Due to their lack of understanding of the SLA theory and research (Richards, 2006; Tomlinson, 2013, 2016), the practitioners often confuse language teaching methodologies/approaches with language learning principles. There is little doubt that the concepts of language teaching methodologies and language learning principles are closely linked with each other and there 
are multiple overlaps between the two, but it is also true that there is a fundamental difference between these two constructs. I explain this difference below.

A language teaching methodology/approach is a larger construct which may consist of several theoretical perspectives called language learning principles (Larsen-Freeman \& Anderson, 2011). A language learning principle is a part of a language teaching methodology; it alone does not formulate a complete language teaching methodology. In other words, it can be said that language learning principles are the building blocks of a language teaching methodology/approach. Moreover, a language teaching methodology is theoretical in nature and it represents the abstract part (Larsen-Freeman \& Anderson, 2011); whereas, the language learning principle underlying a language teaching methodology is its practical part as it helps to bring the language teaching methodology into practice. The success of a language teaching methodology and its usefulness depends on a number of factors. For instance:

- How strong is the theoretical construct of the principles upon which a language teaching methodology is based?

- How far do the practitioners understand the principles formulating the theoretical construct of a language teaching methodology? The stronger is the practitioners' understanding, the better language teaching and learning will be.

- How effectively do the practitioners implement the language teaching methodology?

The above factors of a successful language teaching methodology suggest that to promote effective language teaching and learning, it is important for the practitioners that they should not only have a complete understanding of the theoretical principles underlying a language teaching methodology but must also practice them properly. However, practically, it has been observed that due to a lack of understanding of the theoretical concepts, the practitioners implement a language teaching methodology only partially. Consequently, they fail to achieve the desired results of effective language teaching and learning. Therefore, it is important that the distinction between language methodology and language learning principles should be made clear to the practitioners, as they may not be able to teach effectively unless and until they become aware of this distinction.

The difference between a language teaching methodology/approach and language learning principles can further be explained with the help of the example of communicative language teaching (CLT) which is a widely used language teaching approach in modern times. Based on our experience as language teachers, classroom observers, and researchers, we (the researchers) have observed that a general perspective about CLT (particularly in the ESL/EFL contexts) is that it aims to enhance only speaking skills and cannot serve as an effective language teaching approach to teach linguistic forms1. Therefore, it has been often observed that most of the English language course book developers and English language teachers (particularly in the ESL/EFL contexts) rely on a structural approach to language teaching. CLT is brought to use only when the intention is to teach the speaking skills. But in reality, when we look at the language learning principles underlying CLT, we find that CLT is equally useful in teaching both language skills and linguistic forms. It depends on how well a practitioner is aware of the language learning principles underlying CLT and how well they implement these principles. For instance, some important principles underlying CLT are:

- Language learning enhances when learners are engaged in real-life-like instances of communicative language use with the help of language learning activities and tasks.

- Language learning enhances when learners are provided with more opportunities to interact in the $\mathrm{L} 2$ and hence produce more output.

- Language learning takes place when learners negotiate for meaning by using the target language.

- Language learning takes place when learners are provided with a rich repertoire of linguistic input with the help of communicative activities and tasks.

- Language learning takes place when learners are provided with more opportunities for noticing linguistic forms and drawing their conclusions about how language works instead of providing them ready-made rules of language through explicit instruction of grammar rules.

- The provision of both free and guided practice of language production helps language learning. (Larsen-Freeman \& Anderson, 2011) 
The above example clearly shows how a language teaching methodology/approach may consist of multiple language learning principles. Moreover, it can be noticed that these principles focus on communicative competence and language learning in general, without a particular focus on any one or more skills of communication. Additionally, some of the principles of CLT given above, such as, principle number five, clearly focus on learners' understanding of linguistic forms, which is generally winked at by the practitioners who, as mentioned above, perceive that CLT deals only with developing learners' speaking skills in the target language, and does not help in learning linguistic forms. Furthermore, it can also be observed that all of the above given CLT language learning principles have sufficient theoretical background in the SLA research. Hence, CLT can only be implemented properly if the practitioners are aware of the theoretical and research background of these principles that lay the foundation of CLT. Apart from the researchers' observation in ESL/EFL context, the practitioners' lack of understanding of the SLA theory and research has also been reported by Tomlinson $(2013,2016)$ who states that the practitioners in general hold a perspective that the main aim of CLT is to provide learners with more opportunities for communicative activities and for using language for functional purposes. Tomlinson $(2013,2016)$ further observes that based on a generally held perception that CLT is not an effective approach to teach linguistic forms, many global and local ELT materials/course books mostly rely on the explicit instruction of grammar rules with the help of a structural syllabus, whereas the inclusion of activities and tasks is done to give learners the practice of the speaking skills only.

\section{Language teaching materials and SLA theory}

The evaluation studies of language teaching materials/course books reveal that the practitioners still exist in the older era of the method-driven stage of SLA research instead of coming closer to the theory-driven stage of SLA (Ellis, 2001; Lightbown; 2000; Nassaji and Fotos, 2007) (details of method-driven stage and theory-driven stages of SLA are given below). In reality, the theories of language learning developed during the last three decades of SLA research have much to offer to the practitioners to develop and implement a comprehensive model of language learning in language teaching materials (Richards, 2006). A careful analysis of the latest English language course books/materials (both global and local ELT course books) in various countries across the world shows that they are designed by keeping in mind the general and broader perspective of language teaching methodology instead of focusing on the specific and minute level of the principles of language learning. On account of a lack of understanding of the theoretical principles of SLA, the practitioners are unable to incorporate the language learning principles in language pedagogy and language teaching materials.

The language learning principles presented in the SLA theory (for details, see Ellis, 2005a; Richards, 2006; Tomlinson, 2013, 2016) provide the theoretical construct of SLA. They are presented, argued, analytically analysed and then accepted or refuted by the theorists on the basis of their empirical research published in research journals and books. Each language learning principle deals with one aspect of language learning, and since the 1980s, the theorists have presented, argued, and analytically analysed a large number of principles which play a significant role in language learning. Ellis (2010) states that during the past three decades, a great deal of research has been carried out on various aspects of SLA. All these studies have made SLA a rich treasure of theoretical perspectives, but very little of this theoretical treasure has been put into practice in language pedagogy, especially in the field of materials development (Ellis, 2010). Robbins (2003, p. 59) also accepts this reality and says, 'to date, much SLA research remains within categorical lists, little of which has been translated into teaching materials.' Henceforth, Richard (2006) affirms that to promote effective language teaching and learning, it is important for the practitioners to keep themselves updated with the changing state of language learning theories and to incorporate them in both language pedagogy and language teaching materials.

Now, before going into further details of the gap existing between the theorists and the practitioners, it is pertinent to give a brief review of the SLA research and its different stages since its inception as an independent field of inquiry. This will help us to develop our understanding of various theoretical perspectives and principles of language learning presented in the SLA research so far. It will also enlighten us about which language learning principles have stronger theoretical background and, therefore, are of key importance for 
effective language teaching and learning. It will also help us understand how and why the practitioners did not benefit much from the theoretical principles of language learning.

\section{A brief history of the SLA research and theory}

The onset of SLA as an independent field of study in the broader field of applied linguistics dates back to the later part of the 1960s. Ellis (2001) and Lightbown (2000) provide a comprehensive review of the SLA research focusing on various pedagogical issues. Nassaji and Fotos (2007) provide a comprehensive overview of the SLA research since its inception by referring to a large number of studies that focused on various pedagogical and theoretical issues in SLA. Ellis (2001, cited in Nassaji \& Fotos, 2007) divides the SLA research into three broader stages:

- Method-driven stage

- Theory-driven stage

- Theory-testing stage

The first phase of SLA research is mostly method-driven. It comprises experimental studies conducted in the 1960 s and 1970s which were mainly directed towards making a comparison between various language teaching methodologies/approaches to investigate whether these methodologies/approaches focus on the implicit or explicit instruction of linguistic forms. However, these studies were not intended to categorize the language teaching methodologies as more or less helpful.

The second phase of SLA research is theory-driven. It consists of various theoretical perspectives presented in the 1980s and 1990s. Some of the important theoretical perspectives presented during this era are input hypothesis (Krashen, 1981), role of attention and noticing in SLA (Schmidt, 1993, 2001), developmental sequence of language in both naturalistic and instructed language learning contexts (Pienemann, 1984, 1989), and difference between the two types of language knowledge, namely explicit and implicit knowledge (Krashen, 1981; Bialystok, 1990, 1994; N. Ellis, 1993, 1994; DeKeyser, 1995, 1997; Ellis, 2004, 2005b).

The third phase of SLA research consists of various research studies that aim to test the validity of theoretical claims of SLA research. During this period, the researchers mainly focused on investigating the theoretical claims further. For instance, many research studies investigated how attention and noticing function in language learning (Leow, 2001; Schmidt, 2001). Likewise, the research studies related to the developmental sequences of language learning explored whether developmental sequence remains similar or changes in case of first and second language acquisition. Some studies investigated the effect of instruction on the developmental sequence of language (Pienemann, 1998; Spada \& Lightbown, 1999). Many research studies focused on the relationship between implicit and explicit knowledge in the form of three interface positions, namely non-interface position (Krashen, 1993), stronginterface position (Dekeyser, 1997) and weak-interface position (Ellis, 2004, 2005b). Following these three stages, the next most required and needful phase of SLA research is the application and implementation of SLA theories in real language learning contexts.

Having explained different stages of SLA research, it is a worth mentioning that most of the research in SLA, since its onset, is directed towards instructed language learning, and these studies have mostly been carried out in controlled settings. The SLA researchers have been mainly interested in exploring various principles of instructed language learning. The underlying purpose of all such research studies has been to explore how formal or instructed language learning process can be brought closer to the naturalistic process of language acquisition to promote effective methods and strategies of L2 acquisition. According to Ellis (2005a), there had been a considerable controversy about some basic issues in SLA and instructed language learning. For example, there were divergent views about whether the instruction should focus on forms with the help of a structural syllabus, emphasizing the learning of grammatical features; or it should follow the principle of focus-on-form that believes in learners' learning of linguistic features through their experiential self-discovery with the help of communicative activities in a task-based syllabus. Similarly, there had also been a disagreement as to whether the learning of an L2 should be based on explicit instruction of grammar or it should focus on developing learners' L2 implicit knowledge. In addition, the age 
or stage at which the instruction of grammatical features should start is also a debatable issue (Ellis, 2005a).

Though during the last two decades, the SLA research has addressed many theoretical controversies as mentioned above, at present, there has been little controversy at the level of theory. For instance, now a large number of researchers agree that focus-on-form is a better approach to language teaching as compared to focus-on-forms. The theorists also agree that the main purpose of language teaching and learning should be to develop learners' communicative competence. Similarly, a large number of researchers agree that 'competence in an L2 is primarily a matter of implicit knowledge' (Ellis, 2005a, p. 214). Therefore, the real purpose of language teaching and learning should be to develop learners' L2 implicit knowledge (Ellis, 2005a). However, despite the fact that theoretical controversies have been reduced in the present times, the difference still lies between SLA theory and its implementation (Richards, 2006).

Besides focusing on the methodology and procedures in SLA, the theorists since the 1980s have presented, argued, and analytically analysed a large number of principles which, according to them, play a significant role in language learning. Some important language learning principles presented by the theorists during the theory driven-stage of SLA research are input hypothesis (Krashen, 1981), input processing model, (VanPatten, 1996), interaction hypothesis (Long, 1996), role of noticing and attention in language learning (Schmidt, 1995, 2001), role of output in language learning (Swain, 1995), negotiation for meaning, and formfocused instruction (Long, 1991). Many other researchers have also worked on various aspects associated with these theoretical perspectives. The theorists' main aim in investigating and presenting these principles of language learning is to explore the language learning process. Based on these research studies, the researchers (such as Ellis, 2005a; Richards, 2006; and Tomlinson, 2013, 2016) have attempted to combine the most important and effective language learning principles to develop a comprehensive model of language learning. Now, we discuss these principles which are named as the principles of instructed language learning.

\section{Principles of instructed language learning}

In SLA, there is a multitude of perspectives about language acquisition. These perspectives or principles have been investigated and argued about by a large number of researchers. Some of these perspectives/principles are unanimously agreed upon by many theorists and researchers. For example, based on a large number of research studies, the researchers (Ellis, 2005a; Richards, 2006; Tomlinson, 2013, 2016), to a large extent, have agreed upon a set of language learning principles. Although there are some variations in the principles given by Ellis (2005a), Richards (2006), and Tomlinson (2013, 2016), yet these principles are similar to a large extent. A brief description of the principles that are common in the sets of principles presented by Ellis (2005a), Richards (2006), and Tomlinson $(2013,2016)$ is given below.

\subsection{Input}

Input plays an important role in language learning in both naturalistic and instructed language learning contexts. Language learning is a slow and gradual process. In case of L1 acquisition, children normally take two to five years to attain complete grammatical proficiency in language, and the variance in the speed of language acquisition depends on the quality of and exposure to input. Same is the case with L2 acquisition. The more a learner is exposed to L2 linguistic input, the better and quicker language learner she/he becomes (Ellis, 2005a). Krashen $(1981,1993)$ puts lots of emphasis on the role of input in language acquisition and says that to promote successful language acquisition, it is important to make the input comprehensible. Ellis (2005a) notes that input can be made comprehensible either by modifying it or with the help of contextual props. Some other researchers are of the opinion that input should be rich enough to provide sufficient opportunities for extracting implicit information about the language which a learner can use in real-life, meaningful communication (Ellis, 2008; Tomlinson, 2013, 2016).

\subsection{Noticing and attention}

According to Schmidt (1994, 2001), simply input is not enough in SLA; noticing and conscious attention to specific linguistic forms are equally important. Schmidt $(1994,2001)$ 
asserts that input cannot become intake unless it is noticed. Learners' willing attention to linguistic forms in the input, whether it is conscious or incidental, plays a vital role in language learning (Schmidt, 2001). However, Schmidt (2001) makes it clear that 'noticing' means attending to linguistic forms as they appear in the input, not the conscious awareness of grammatical rules.

\subsection{Focus on form and meaning}

Researchers have suggested different methods of noticing the input. One method is to provide direct instructions to learners which is usually termed as deductive teaching or the provision of explicit metalinguistic knowledge to learners (Ellis, 2010; Tomlinson, 2013, 2016). However, this is an old and traditional method of teaching and is not recommended by a large number of researchers, educationists and experts in modern times. The other method of making learners notice the linguistic input, which is broadly recommended by modern theorists and researchers, is to let the learners draw their conclusions by using experiential selfdiscovery technique (Richards, 2006; Tomlinson, 2013). This experiential self-discovery technique can also be called the inductive method of language teaching in which a teacher performs the role of a facilitator rather than that of an instructor and lets the learners draw their conclusions. In SLA, a method for carrying out this experiential discovery technique is focus-on-form.

Focus-on-form is an instructional approach in which learners' attention is overtly drawn to linguistic forms in the lessons where the primary focus is on meaning and communication (Long, 1991). It is quite opposite to focus-on-forms approach in which the primary focus of instruction is on linguistic forms' (Afitska, 2015, p. 58). According to Ellis (2001), focus-onform instruction can be incidental or planned. In case of incidental focus-on-form (which is also called extensive focus-on-form) multiple linguistic items are addressed in a single lesson; whereas in planned focus-on-form (which is also called intensive focus-on-form) only preselected items are attended to in a lesson. The availability of planned focus-on-form can be ensured in the input, whereas the incidental focus-on-form takes place in the feedback (Ellis, 2001). Initially, the concept of focus-on-form was taken as 'a general orientation to language as form' (Ellis, 2005, p. 212); but later on, Schmidt (2001) added the element of attending to form for which he suggested that paying conscious attention to specific linguistic forms and noticing them either in the input or in implicit corrective feedback is necessary. Schmidt (2001) and Long (1991) explain that focus-of-form underlies form-function mapping, that is, attending to linguistic forms with the purpose of functions they perform in meaningful communication. However, Schmidt (2001) makes it clear that 'noticing' means attending to linguistic forms as they appear in the input, not the conscious awareness of grammatical rules.

\subsection{Interaction}

The process of experiential self-discovery can be achieved by involving learners in meaningful interaction leading to the understanding of both form and meaning. The learners should be provided with sufficient opportunities for language use in real-life-like situations; as, according to interaction hypothesis (Long, 1996), language acquisition is promoted when learners are engaged in meaningful interaction in which they primarily focus on encoding and decoding messages. Moreover, learners' involvement in meaningful interaction helps them activate their linguistic resources. Interaction also helps learners to negotiate for meanings while interacting with one another; and this negotiation for meanings proves helpful in language acquisition.

\subsection{Output}

It is not only the input that plays a significant role in language learning, producing output is also equally important (Swain, 1995). Further, output is not only the source of producing and practising the language, but it also serves as auto-input to learners (Ellis, 2008; Swain, 1995). When producing output, learners unconsciously monitor their own produced language which helps them in their syntactic processing and facilitates language learning. The output also helps learners to automatise their existing linguistic knowledge. Output in the form of free and controlled production tasks promotes language learning.

\subsection{Implicit and explicit instruction}

Instruction should be directed to developing both implicit and explicit knowledge. However, priority should be given to the development of implicit knowledge as a large number 
of researchers agree that the real purpose of language learning should be to develop learners' L2 implicit knowledge (Ellis, 2005). Implicit knowledge is unconscious and procedural. and It is acquired through linguistic input a learner is exposed to. In contrast, explicit knowledge is conscious, learnable and verbalizable. It is acquired by paying conscious attention to linguistic rules. It is widely accepted by researchers that 'competence in an L2 is primarily a matter of implicit knowledge' (Ellis, 2005a, p. 214). As the ability to communicate fluently is based upon implicit knowledge, researchers agree that the development of L2 implicit knowledge 'should be the ultimate goal of any instructional programme' (Ellis, 2005a, p. 214). In this regard, the differences of opinion exist only about the ways of acquiring implicit knowledge in the form of three different interface positions: (i) non-interface position, (ii) strong interface position, and (iii) weak interface position. The proponents of non-interface position (e.g., Krashen, 1981) hold the opinion that explicit and implicit knowledge are completely different and it is not possible to convert explicit knowledge into implicit knowledge. Therefore, the explicit instruction of linguistic forms in the form of focus-on-forms with the help of a structural syllabus does not help to promote learners' L2 implicit knowledge. The adherents of strong interface position (e.g., DeKeyser, 1997) accept the possibility of transferring explicit knowledge into implicit knowledge through practice and proceduralization of explicit knowledge. Therefore, they believe in providing maximum practice of linguistic forms through communicative practice. The third type of researchers (e.g., Ellis, 1994, 2004, 2005b), who speak in favour of a weak-interface position, argue that there is some possibility of converting explicit knowledge into implicit through noticing. The proponents of weak-interface position state that explicit knowledge can facilitate implicit knowledge when it is acquired through experiential self-discovery with the help of consciousness-raising tasks which help learners to draw their conclusions about the grammatical rules of a language through noticing. The explicit grammatical rules learnt with the help of self-discovery facilitate implicit knowledge of language which is the ultimate goal of language acquisition.

Having maintained the role of instruction in SLA pedagogy, recent research in SLA has revealed the inefficacy of the methods and materials used in instructed language learning. One of the most highlighted limitation of SLA pedagogy is teaching individual grammatical items with the help of a structural syllabus, as it does not prove helpful in promoting target language acquisition (Long, 1991). The old methods of language teaching (such as grammar translation method and audio-lingual method) see learners as passive recipients of knowledge who first should learn the rules of the target language and then bring them to their use. This is why, all such old language teaching methods focus on the presentation, practice and production (PPP) model of language teaching. For this, they mostly favour the use of a structural syllabus (Ellis, 2005). This view of language learning is based on the behaviouristic model of language learning. The recent research in SLA has changed this approach to language learning and, as a result, a paradigm shift has occurred from the explicit instruction of language rules to selfdirected language learning through communicative language teaching. However, the use of only a communicative approach has also been found inadequate in SLA as it does not promote accuracy (Swain, 1998; Swain \& Lapkin, 1998). In order to overcome the drawbacks of both older and modern language teaching methods/approaches, the recent research has provided two solutions.

- It emphasises the need for self-directed learning which can be carried out if the learners attend to a target form by noticing the target feature in the input (Ellis, 2001; Schmidt, 2001). This principle promotes an inductive method of teaching and learning a language.

- It believes in providing leaners with the opportunities for using the target forms in the output they produce because it helps learners find out the gap between their knowledge of a target language form (their interlanguage state) and the actual correct target language form (Swain, 2005).

The SLA theorists have attempted to put all these principles together in the form of an approach to language teaching called focus-on-form approach. During the last two decades a great deal of research has been carried out on focus-on-form instruction from diverse perspectives, such as 'its impact on language learning, its use in communicative language teaching (CLT) classrooms, its effectiveness depending on type, and its use by learners and by teachers' (Afitska, 2015, p. 58). However, one area that has been neglected so far is the role 
of focus-on-form instructional approach in materials development. Due to its wide spectrum in ELT and strong theoretical and research background, the focus-on-form approach to language teaching might play a significant role in materials development. Moreover, it has been widely accepted by the researchers (Ellis, 2010, Nassaji \& Fotos, 2007; Richards, 2006; Robbins, 2003; Tomlinson, 2013, 2016) that there has been little research in the field of materials development from the viewpoint of SLA theories. As focus-on-form has emerged as a strong theoretical construct in SLA over the last two decades, it is important to see its role in materials development and syllabus designing.

\section{Conclusion}

Reviewing all practical aspects of SLA theory and research, we infer that there have been many transitional developments in the theories, methodologies and principles in SLA pedagogy since its inception. However, bringing these transitions into practice through a suitable, up-to-date methodology and materials is found to be a neglected aspect. Presently, the SLA theory and research has stepped far away from the old, stereotype concepts of second language learning and teaching, such as focus on linguistic forms, explicit instruction of grammatical rules, deductive approach to learning and teaching, use of traditional lecturebased methods. Now, the SLA theory and research is heading towards the modern, innovative concept of focus-on-form by amalgamating the principles, such as self-directed learning, implicit knowledge, inductive learning through self-discovery and communicative language learning. However, SLA practitioners (material developers and teachers) are still seen to base their practices in old theories and methods. The teachers usually follow a structural syllabus and its associated course books/materials as it adheres to a focus-on-forms approach by teaching linguistic forms through explicit instruction. Moreover, the course books and materials, which are currently being used, usually do not entertain the functional aspects of SLA. These materials aim to develop learners' reading and writing skills only, while they completely ignore to enhance learners' speaking and listening skills through real-life-like activities and materials. Hence, to bring effectiveness in second language learning and teaching, there is a need to bridge the gap between what SLA theorists and researchers have concluded until now about the principles and methods in SLA theory and what teachers and material developers are actually practising in SLA pedagogy. In the present paper, the overall review of SLA theory and practice implies that there is a need to shift from focus-on-formS approach to focus-on-form approach in SLA pedagogy. The practical potential of focus-on-form approach lies in the fact that it encompasses a large number of perspectives in applied linguistics, that is, SLA theory, language pedagogy, and language teaching materials. From theoretical point of view, it covers the aspects of input, attention, noticing, interaction, output, and feedback. From the viewpoints of the type of knowledge, it entails both implicit and explicit knowledge of language. From practical perspectives, it includes teachers, learners, and language teaching materials. However, it is worth-consideration here that although, a lot of work on focus-on-form approach has already been done, it still needs more exploration. A large amount of research on focus-on-form has been directed towards its theoretical perspectives but very little research has been carried out on its practical aspects, especially in the context of instructed language learning and materials development. Therefore, it is important to explore focus-on-form and its sub-aspects (input, attention, noticing, interaction, output, and feedback) in the fields of materials development and instructed language learning as well. Such a research will not only add something more to the field of materials development but will also open new horizons in language pedagogy from both theoretical and practical perspectives.

\section{Endnote}

Here we are particularly referring to the Asian ESL/EFL contexts, such as Pakistan and Saudi Arabia, where we (the researchers) have worked as English language teachers, professional development specialists, classroom observers, and teacher evaluators. Moreover, the literature (such as Coleman \& Capstick, 2012; Holliday, 1994, 2016; McKay, 2003) also confirms the reality of this claim. However, it is clarified that this claim does not stand valid in the countries where English is the first/native language, such as Australia, Canada, New Zealand, the United Kingdom and the United States. 


\section{Acknowledgement}

This research paper is an outcome of the authors' personal research interests. It received no specific grant from any funding agency in the public, commercial, or not-for-profit sectors.

\section{References}

Afitska, O. (2015). Role of focus-on-form instruction, corrective feedback and uptake in second language classrooms: Some insights from recent second language acquisition research. The Language Learning Journal, 43(1), 57-73.

Bialystok, E. (1990). The competence of processing: Classifying theories of second language acquisition. TESOL Quarterly, 24(4), 635-648.

Bialystok, E. (1994). Representation and ways of knowing: Three issues in second language acquisition. In N. Ellis (Ed.), Explicit and implicit learning of languages (pp. 549-569). London: Academic Press.

Coleman, H., \& Capstick, T. (2012). Language in education in Pakistan: Recommendations for policy and practice. Islamabad: British Council.

Dekeyser, R. (1995). Learning second language grammar rules: An experiment with a miniature linguistic system. Studies in Second Language Acquisition, 17(3), 379-410.

DeKeyser, R. (1997). Beyond explicit rule learning: Automatizing second language morphosyntax. Studies in Second Language Acquisition, 19(2), 195-221.

Ellis, N. (1993). Rules and instances in foreign language learning: Interactions of explicit and implicit knowledge. The European Journal of Cognitive Psychology, 5(3), 289-318.

Ellis, N. (1994). Explicit and implicit learning of languages. London: Academic Press.

Ellis, R. (2001). Introduction: Investigating form-focused instruction. Language Learning, $51(1), 1-46$.

Ellis, R. (2004). The definition and measurement of L2 explicit knowledge. Language Learning, 54(2), 227-275.

Ellis, R. (2005a). Principles of instructed language learning. System, 33(2), 209-224.

Ellis, R. (2005b). Measuring implicit and explicit knowledge of a second language. Studies in Second Language Acquisition, 27(1), 141-172.

Ellis, R. (2008). The study of second language acquisition (2nd ed.). Oxford: Oxford University Press.

Ellis, R. (2010). Second language acquisition research and language teaching materials. In N. Harwood (Ed.), English language teaching materials: Theory and practice (pp. 33-57). Cambridge: Cambridge University Press.

Holliday, A. (1994). Appropriate methodology and social context. Cambridge: Cambridge University Press.

Holliday, A. (2016). Appropriate methodology: towards a cosmopolitan approach. In G. Hall (Ed.), Routledge handbook of English language teaching (pp. 265-77). London: Routledge.

Krashen, S. (1981). Second language acquisition and second language learning. Oxford; Pergamon Press.

Krashen, S. (1993). The effect of formal grammar teaching: Still peripheral. TESOL Quarterly, 27(4), 722-725.

Larsen-Freeman, D., \& Anderson, M. (2011). Techniques and principles in language teaching (3rd ed.). Oxford: Oxford University Press.

Leow, R. (2001). Attention, awareness and foreign language behaviour. Language Learning, 51(1), 113-155.

Lightbown, P. (2000). Classroom SLA research and second language teaching. Anniversary article. Applied Linguistics, 21(4), 431-462.

Long, M. (1991). Focus on form: a design feature in language teaching methodology. In K, de Bot, R. Ginsberg and C. Kramsch (Eds.). Foreign language research in cross-cultural perspectives (pp. 39-52). Amsterdam: John Benjamin

Long, M. (1996). The role of linguistic environment in second language acquisition. In W. Ritchie and T. Bhatia (Eds.), Handbook of second language acquisition (pp. 413-468). San Diego: Academic Press.

McKay, S. L. (2003). Toward an appropriate EIL pedagogy: Re-examining common ELT assumptions. International Journal of Applied Linguistics, 13(1), 1-22.

Nassaji, H. (2005). The relationship between second language acquisition research and language pedagogy: EFL and ESL teachers" perspective. Paper presented at the 
Canadian Association of Applied Linguistics (CAAL), University of West Ontario, London, Ontario, Canada.

Nassaji, H., \& Fotos, S. (2007). Issues in form-focused instruction and teacher education. In S. Fotos, \& H. Nassaji (Eds.), Form focussed instruction and teacher education: Studies in honour of Rod Ellis (pp. 7-15). Oxford: Oxford University Press.

Pienemann, M. (1984). Psychological constraints on the teachability of languages. Studies in Second Language Acquisition, 6(2), 186-214.

Pienemann, M. (1989). Is language teachable? Psycholinguistic experiments and hypothesis. Applied Linguistics, 10(1), 52-79.

Pienemann, M. (1998). Language processing and second language development: Processability theory. Amsterdam: John Benjamins.

Richards, J. C. (2006). Materials development and research - making the connection. RELC, $37(1), 2-26$.

Robbins, D. (2003). Vygotsky's and A. A. Leontive's semiotics and psycholinguistics: Applications for educations, second language acquisition, and theories of language. Westport, Conn.: Praeger Publishers.

Schmidt, R. (1993). Awareness and second language acquisition. Annual Review of Applied Linguistics, 13, 206-226.

Schmidt, R. (2001). Attention. In P. Robinson (Ed.), Cognition and second language instruction (pp. 3-32). New York. Cambridge University Press.

Spada, N., \& Lightbown, P. M. (1999). Instruction, first language influence, and developmental readiness in second language acquisition. The Modern Language Journal, 83(1), 1-22.

Swain, M. (1995). Three functions of output in second language learning. In G. Cook, B. Seidhofer (Eds.), Principles and practice in the study of language (pp. 125-144). Oxford: Oxford University Press:

Swain, M. (1998). Focus on form through conscious reflection. In C. Doughty and J. Williams (Eds.), Focus on form in second language acquisition (pp. 42-63). Cambridge: Cambridge University Press.

Swain, M. (2005). The output hypothesis: Theory and research. In E. Hinkel (Ed.), Handbook on research in second language teaching and learning (pp. 471-483). Mahwah, NJ: Lawrence Erlbaum Associates.

Swain, M., \& Lapkin, S. (1998). Interaction and second language learning: Two adolescent French immersion students working together. The Modern Language Journal, 82(3), 320-337.

Tomlinson, B. (2005). Testing to learn. ELT Journal, 59(1), 39-46.

Tomlinson, B. (2013). Second language acquisition and materials development. In B. Tomlinson (Ed.), Applied linguistics and materials development (pp. 11-29). London: Bloomsbury.

Tomlinson, B. (2016). Achieving a match between SLA theory and materials development. In B. Tomlinson (Ed.), SLA research and materials development for language learning. 322.

VanPatten, B. (1996). Input processing and grammar instruction in second language acquisition. Ablex, Norwood, NJ. 